\title{
Isolated Frozen Eyes in Posterior Circulation Stroke
}

\author{
Sampath kumar NS* and Sangamithra G \\ Department of Neurology, Narayana Medical college \& Hospital, India
}

Submission: January 03, 2019; Published: March 18, 2019

*Corresponding author: Department of Neurology, Narayana Medical college \& Hospital, India

\begin{abstract}
Blepharoptosis, commonly referred to as ptosis is an abnormal drooping of the upper eyelid. This condition has multiple etiologies and is seen in all age groups. Ptosis may be due to a myogenic, neurogenic, aponeurotic, mechanical or traumatic cause. We experienced a case of severe bilateral ptosis occurring after midbrain infarction. At presentation the patient had difficulty opening his eyes as the only clinical manifestation, but he did not have any limb weakness or ataxia or any other features that are usually seen with midbrain infarction.
\end{abstract}

Keywords: Blepharoptosis; Ptosis; Midbrain infarction; Embolic stroke; Oculomotor; Bilateral ptosis; Midbrain; Nervous system; Abnormalities; Behavioral abnormalities; Oculomotor; Parasympathetic; Intoxication

Abbrevations: PCA: Posterior Cerebral Artery; PAD: Peripheral Arterial Disease;

\section{Introduction}

The midbrain is supplied by the Posterior Cerebral Artery (PCA), basilar artery, superior cerebellar artery, and anterior choroidal artery. The midbrain is often affected in patients with embolic stroke occurring in the posterior circulation, usually with the concomitant involvement of other structures, such as the pons, thalamus, and the cerebellum. Infarction limited to the midbrain is rare. The reported prevalence of pure midbrain infarction varies from $0.7 \%$ to $2.3 \%[1,2]$. Ptosis could be caused by oculomotor nerve palsy in the patients with midbrain infarction. In several cases, bilateral ptosis showed the clinical characteristics of midbrain infarction $[1,3,4]$.

\section{Case Report}

A 40-year-old man, a chronic smoker with a previous history of Peripheral Arterial Disease (PAD) presented to the OPD due to sudden onset inability to open his eyes and blurred vision. The patient was conscious and oriented. Examination revealed pronounced bilateral ptosis, with dilated and non-reactive pupils. There was marked limitation of adduction, elevation and depression in both eyes in the movement of both eyeballs. Abduction was normal with gaze evoked horizontal nystagmus in both eyes on abduction. There were no other findings of central nervous system disease that could cause ptosis from brain imaging, and no evidence of other orbital disease-causing ptosis in an ophthalmologic examination. Muscle strength rated using the Medical Research Council Scale was grade 5/5 in both upper limbs and right lower limb (left lower limb amputated due to PAD). Other cranial nerves were normal. No sensory loss was seen. There were no cerebellar signs. In view of acute infarcts, he was started on anticoagulants, statins and neuro protectives. His ptosis showed mild improvement after 3 days of treatment.

\section{Discussion}

Paramedian midbrain infarction results from occlusion of the branches (the Medial Mesencephalic Branch [MMB]) that diverge from the proximal portion of the PCA before the branching of the posterior communicating artery [3]. The MMB is divided into the superior MMB, which supplies the rostral part of the midbrain, and the inferior MMB, which supplies the caudal part of the midbrain. Bilateral midbrain infarction usually produces alterations in the level of consciousness, cognitive abnormalities, behavioral abnormalities and eye movement disorders [4]. Eye movement disorders include oculomotor nerve palsy, vertical gaze palsy, and internuclear ophthalmoplegia.

\section{Brain diffusion-weighted imaging and apparent diffu- sion coefficient map at clinical onset}

a. Axial diffusion-weighted imaging demonstrates increased signal in the bilateral paramedian midbrain, in the right half of vermis of cerebellum and left thalamus (Figures 1-3). 


\section{Open Access Journal of Neurology \& Neurosurgery}

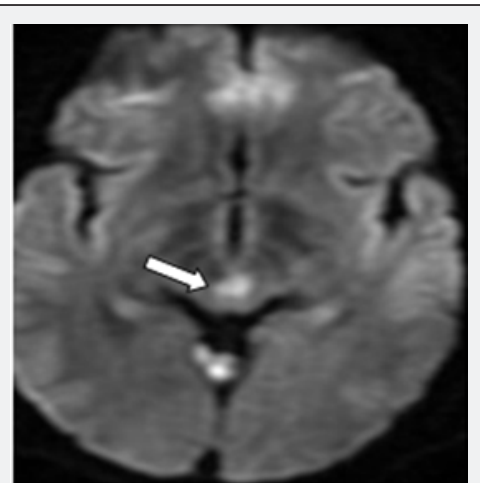

Figure 1: MRI Brain axial diffusion weighted image (DWI) revealed acute infarct in the paramedian midbrain.

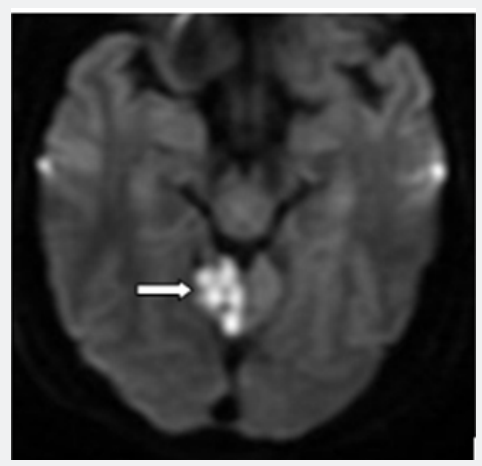

Figure 2: MRI Brain axial diffusion weighted image (DWI) revealed acute infarct in the right half of vermis of cerebellum.

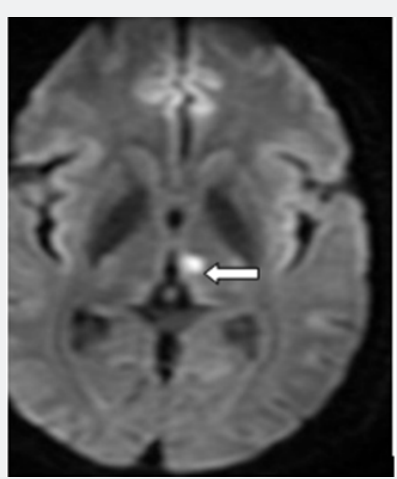

Figure 3: MRI Brain axial diffusion weighted image (DWI) revealed acute infarct in the left thalamus.

b. Apparent diffusion coefficient map demonstrates hypointense signal in corresponding areas, consistent with restricted diffusion.

The nucleus of the oculomotor is located at the ventromedial part of the central gray in the rostral midbrain and consists of the lateral somatic cell column, caudal central nucleus, and medial cell column. The Edinger-Westphal nucleus is called the accessory oculomotor nerve nucleus and is located at the dorsomedial region of the oculomotor nerve nucleus [5]. In our case, ocular symptoms were manifested by bilateral oculomotor nerve palsies. Abnormal movement of extraocular muscles implies involving the lateral and medial cell column, which regulates extraocular muscles including the inferior rectus, inferior oblique, medial rectus and superior rectus muscles. The abnormality of the pupillary function implies involvement of the Edinger-Westphal complex, which leads the parasympathetic nerve fibers to the sphincter pupillae muscles and ciliary muscles over the ciliary ganglion.

Bilateral ptosis is the hallmark of involvement of the central caudal nucleus, which regulates the levator palpebrae superioris muscle on both sides. Bilateral ptosis was reported in a few reports that presented the clinical characteristics of midbrain infarction. In Kim \& Kim [1] reported the clinical findings of 40 patients with pure midbrain infarction. Ocular motor manifestations were seen in 21 (53\%) patients. Among the 40 patients, 12 had ptosis, which was unilateral in 10 patients and bilateral in two patients. In Ogawa, et al. [3] reported a clinical study of 21 patients with pure midbrain infarction. Ptosis was present in four patients. Ptosis was unilateral in three patients and bilateral in only one patient. Most patients with bilateral ptosis as a manifestation of midbrain infarction had poor prognosis because the affected midbrain lesions were multiple and broad. In Thurtell \& Halmagyi [4] reported three cases of complete ophthalmoplegia, the combination of bilateral ptosis with loss of all extraocular movements as a manifestation of bilateral paramedian midbrain thalamic infarction. Among these patients, two had died. In a previous study conducted by Ogawa, et al. [3], the patient presenting the bilateral ptosis had bilateral multiple (rostral and caudal) midbrain infarction and a drowsy level of consciousness.

Ptosis may be classified according to various criteria, such as etiology, severity, and levator function. Based on etiology, ptosis has myogenic, neurogenic, aponeurotic, mechanical or traumatic causes [6-8]. Neurogenic ptosis is due to the malfunction or damage of the oculomotor or sympathetic nerve, or central nervous system abnormalities. Other conditions that frequently affect the oculomotor nerve are diabetes, tumors, aneurysms, multiple sclerosis, intoxication with heavy metals and trauma. Usually, neurogenic ptosis can be corrected and may spontaneously resolve if the underlying cause is treated. According to the levator function, the degree ptosis can be classified as poor (0-4 mm), moderate (5-10 mm), or good $(>10$ $\mathrm{mm}$ ). The levator function expressed as the distance between the excursion of the upper lid margin from full downward gaze to full upward gaze [9].

In our case, the levator function was $0 \mathrm{~mm}$ on both eyes. The severity of ptosis was severe with poor levator function. Palpebral fissure height could not be checked because the patient could not open her eyes at all. Mild improvement ( $2 \mathrm{~mm}$ ) of ptosis was seen in right eye after 3 days. Although the patient 
had infarcts in right half of vermis and the thalamus, he did not show any signs of cerebellar, thalamic or pyramidal involvement.

\section{References}

1. Kim JS, Kim J (2005) Pure midbrain infarction: clinical, radiologic, and pathophysiologic findings. Neurology 64(7): 1227-1232.

2. Bogousslavsky J, Maeder P, Regli F, Meuli R (1994) Pure midbrain infarction: clinical syndromes, MRI, and etiologic patterns. Neurology 44(11): 2032-2040.

3. Ogawa K, Suzuki Y, Oishi M, Kamei S (2012) Clinical study of twentyone patients with pure midbrain infarction. Eur Neurol 67(2): 81-89.

4. Thurtell MJ, Halmagyi GM (2008) Complete ophthalmoplegia: an unusual sign of bilateral paramedian midbrain-thalamic infarction. Stroke 39(4): 1355-1357.
5. Donzelli R, Marinkovic S, Brigante L, Nikodijevic I, Maiuri F, et al. (1998) The oculomotor nuclear complex in humans: microanatomy and clinical significance. Surg Radiol Anat 20(1): 7-12.

6. Finsterer J (2003) Ptosis: causes, presentation, and management. Aesthetic Plast Surg 27(3): 193-204.

7. Betharia SM, Kalra BR (1985) Observations on Bell's phenomenon after levator surgery. Indian J Ophthalmol 33(2): 109-111.

8. van Sorge AJ, Devogelaere T, Sotodeh M, Wubbels R, Paridaens D (2012) Exposure keratopathy following silicone frontalis suspension in adult neuro- and myogenic ptosis. Acta Ophthalmol 90(2): 188-192.

9. Finsterer J (2003) Ptosis: causes, presentations, and management. Aesth Plast Surg 27(3): 193-204.

\section{Your next submission with Juniper Publishers will reach you the below assets}

- Quality Editorial service

- Swift Peer Review

- Reprints availability

- E-prints Service

- Manuscript Podcast for convenient understanding

- Global attainment for your research

- Manuscript accessibility in different formats

( Pdf, E-pub, Full Text, Audio)

- Unceasing customer service

Track the below URL for one-step submission https://juniperpublishers.com/online-submission.php 